\title{
References
}

1 Verleden GM, Raghu G, Meyer KC, et al. A new classification system for chronic lung allograft dysfunction. J Heart Lung Transplant 2014; 33: 127-133.

2 Sato M, Waddell TK, Wagnetz U, et al. Restrictive allograft syndrome (RAS): a novel form of chronic lung allograft dysfunction. J Heart Lung Transplant 2011; 30: 735-742.

3 Todd JL, Jain R, Pavlisko EN, et al. Impact of forced vital capacity loss on survival after the onset of chronic lung allograft dysfunction. Am J Respir Crit Care Med 2014; 189: 159-166.

4 Verleden SE, de Jong PA, Ruttens D, et al. Functional and computed tomographic evolution and survival of restrictive allograft syndrome after lung transplantation. J Heart Lung Transplant 2014; 33: 270-277.

5 Barker AF, Bergeron A, Rom WN, et al. Obliterative bronchiolitis. N Engl J Med 2014; 370: 1820-1828.

6 Sato M, Hwang DM, Waddell TK, et al. Progression pattern of restrictive allograft syndrome after lung transplantation. J Heart Lung Transplant 2013; 32: 23-30.

7 Verleden SE, Vasilescu DM, Willems S, et al. The site and nature of airway obstruction after lung transplantation. Am J Respir Crit Care Med 2014; 189: 292-300

\section{Detection of pepsin in sputum: a rapid and objective measure of airways reflux}

\author{
To the Editor:
}

The diagnostic test, Peptest (RD Biomed Ltd, Cottingham, UK), detects pepsin in expectorated saliva and is established as a simple, noninvasive measure of reflux of gastric contents. It has been used to detect pepsin A in patients with both gastro-oesophageal reflux disease (GORD) and extra-oesophageal reflux into the laryngopharynx and airways [1-5].

Reflux has a substantial, but as yet undefined, component in the aetiology of cough hypersensitivity syndrome [6]. Currently evaluation is by the subjective Hull Airways Reflux Questionnaire (HARQ) [7] or objective, but costly and invasive, measures such as 24-h pH-metry, impedance [8], and high resolution manometry $[8,9]$. These current diagnostic pathways have their limitations in detecting low levels of airways reflux that may be sufficient to cause chronic cough. We hypothesised that Peptest could provide simple objective confirmation of airways reflux in unselected patients with chronic cough.

Peptest was used in routine clinical practice in out-patients attending the Hull Cough Clinic at Castle Hill Hospital (Hull, UK), a secondary and tertiary referral centre. Verbal consent was obtained at the time of attendance. Chronic cough was defined as cough lasting $>8$ weeks.

Patients were instructed to provide three expectorated saliva/sputum samples into sample collection tubes (containing $0.01 \mathrm{M}$ citric acid) during daily activities and immediately after three spontaneous coughing episodes. Sample collection was optimised by providing patient leaflets and a video. The presence and concentration of pepsin was measured using Peptest by trained analysts and with a lateral flow-test reader calibrated with known concentrations of pepsin A standard. The lower limit of detection is $16 \mathrm{ng} \cdot \mathrm{mL}^{-1}$ and upper limit of quantification was $500 \mathrm{ng} \cdot \mathrm{mL}^{-1}$. Peptest is specific for pepsin $\mathrm{A}$ (isoforms $1,3 \mathrm{a}, 3 \mathrm{~b}$ and $3 \mathrm{c}$ ) and does not detect pepsin C/Gastricsin (isoform 5) putatively suggested to be expressed in the lungs [10, 11]. As pepsin concentrations do not follow a normal distribution a non-parametric statistical analysis was performed.

We have tested 93 (55 female) chronic cough patients mean \pm SD age 58.4 \pm 13.8 years between August 2014 and December 2014. Smoking status was: smoker $n=5$, nonsmoker $n=55$, ex-smoker $n=24$ and unknown $n=9$. The mean \pm SD HARQ score (upper limit of normal 13) was 31.9 \pm 13.1 and cough duration was $5.6 \pm 7.0$ years. Over a period of 4 months the 93 patients provided 262 evaluable samples for testing. 80 patients had at least one pepsin positive sample $(86.0 \%)$. Pepsin concentrations ranged from 0 to $500 \mathrm{ng} \cdot \mathrm{mL}^{-1}$ with a median (interquartile range (IQR)) of $31 \mathrm{ng} \cdot \mathrm{mL}^{-1}(0-113.5) \mathrm{ng} \cdot \mathrm{mL}^{-1}$.

We previously [1] used a similar triple sampling strategy in a thoroughly investigated normal asymptomatic healthy volunteer population. The absence of gastro-oesophageal reflux was confirmed by $\mathrm{pH}$-impedance testing. In contrast to this chronic cough study these control samples were provided first thing in the morning, $1 \mathrm{~h}$ after lunch and $1 \mathrm{~h}$ after the evening meal. Of the 87 control subjects only 33 were found to have at least one positive sample (37.9\%) but the pepsin concentration in those that were Peptest positive was very low, median (IQR) of $0(0-0)$ ng. $\mathrm{mL}^{-1}$ pepsin, which represents physiological reflux. 

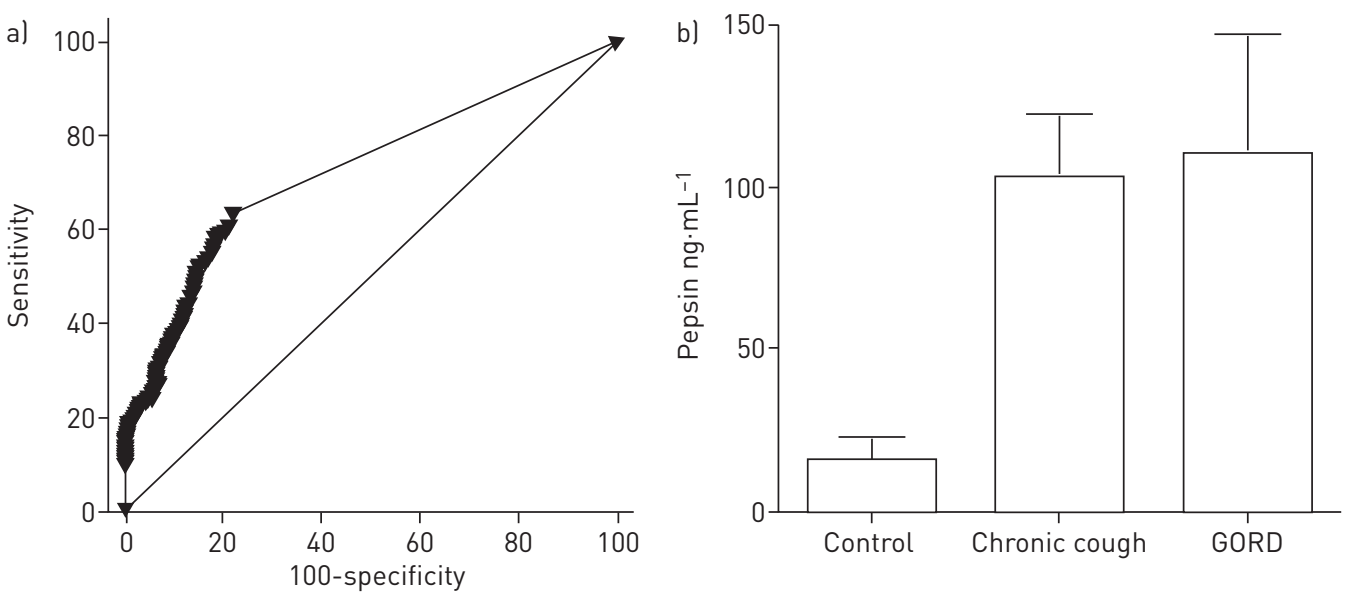

FIGURE 1 a) Receiver operating characteristics curve for pepsin concentration measured in 93 chronic cough patients (262 samples) measured using Peptest (RD Biomed Ltd, Cottingham, UK). b) The mean (95\% CI) pepsin concentration (measured using Peptest) of 93 chronic cough patients and 59 gastro-oesophageal reflux disease (GORD) patients providing samples within $15 \mathrm{~min}$ of a symptomatic episode [12] compared to 87 healthy controls [1].

Patients with chronic cough in our study had significantly increased prevalence of pepsin detection $(\mathrm{p}<0.0001$ Fisher's exact test; $86 \%$ versus $38 \%)$ and increased pepsin concentration $(\mathrm{p}<0.0001$ MannWhitney U-test, $31 \mathrm{ng} \cdot \mathrm{mL}^{-1}$ versus $0 \mathrm{ng} \cdot \mathrm{mL}^{-1}$ ) compared to the control group. There was a significant receiver operating characteristic (ROC) curve $(0.7244, \mathrm{p}<0.0001$ area under the ROC curve) for chronic cough patients against the control population (figure 1a).

Other primary lung pathology, such as COPD or IPF, was present in only $6 \%$ of the patients and did not influence the rate of pepsin detection (prevalence $83 \%$ with lung pathology versus $86 \%$ without lung pathology).

Interestingly, the mean pepsin concentration in this chronic cough population is comparable to the mean pepsin concentration seen in 59 symptomatic GORD patients [12] at the time of symptomatic episodes, as was the prevalence of pepsin detection (80\%). Thus suggesting that the level of pepsin associated reflux seen in chronic cough patients may be pathologically relevant (figure 1b).

Acid suppression medication, usually proton pump inhibitors (PPI), had been prescribed to $30 \%$ of the patients at presentation. Acid suppression did not impact on the detection or concentration of refluxed pepsin (81\%, $37 \mathrm{ng} \cdot \mathrm{mL}^{-1}$ on PPI versus $89 \%, 28.5 \mathrm{ng} \cdot \mathrm{mL}^{-1}$ off PPI; $\mathrm{p}>0.05$ Fisher's exact test). We have previously shown in a randomised double-blind placebo-controlled study of esomeprazole [13] that acid suppression is of no significant benefit in the treatment of airways reflux associated chronic cough. For a patient with airway hypersensitivity a small amount of reflux (usually non-acid) may be sufficient to induce cough [14] and a pro-motility medical strategy (e.g. baclofen, metaclopramide or azithromycin) should be considered.

This prospective cohort study in a real-life setting has demonstrated Peptest has a high sensitivity to detect pepsin in the overwhelming majority of chronic cough patients during symptomatic episodes. Since some reflux is physiological a lack of specificity must be considered. In conjunction with subjective assessment this assay may aid in diagnosis, leading to more appropriate management strategies in chronic cough.

@ERSpublications

Detection of salivary pepsin (Peptest) may be a useful adjunct in the diagnosis of airway reflux http://ow.ly/T7B0l

Vicki Strugala ${ }^{1}$, Andrew D. Woodcock ${ }^{1}$, Peter W. Dettmar ${ }^{1}$, Shoaib Faruqi ${ }^{2}$ and Alyn H. Morice ${ }^{2}$

${ }^{1}$ RD Biomed Ltd, Castle Hill Hospital, Cottingham, UK. ${ }^{2}$ Centre for Cardiovascular and Metabolic Research, Hull York Medical School, University of Hull, Castle Hill Hospital, Hull, UK.

Correspondence: Alyn H. Morice, Centre for Cardiovascular and Metabolic Research, Hull York Medical School, University of Hull, Castle Hill Hospital, Cottingham, East Yorkshire, HU16 5JQ, UK. E-mail: a.h.morice@hull.ac.uk

Received: May 262015 | Accepted after revision: Sept 112015 | First published online: Nov 52015

Support statement: This project was funded in part by the European Union through the Yorkshire Innovation Fund, under the Yorkshire and Humber European Regional Development Fund Programme 2007-2013.

Conflict of interest: Disclosures can be found alongside the online version of this article at erj.ersjournals.com 
Acknowledgements: We gratefully acknowledge the RD Biomed Ltd technical assistance of Jeanine Fisher (Cottingham, UK), the NHS patient management of Karen Welburn and the NHS secretarial assistance of Hanka Remblance (both Centre for Cardiovascular and Metabloic Research, Hull York Medical School, University of Hull, Castle Hill Hospital, Cottingham).

\section{References}

1 Hayat JO, Gabieta-Somnez S, Yazaki E, et al. Pepsin in saliva for the diagnosis of gastro-oesophageal reflux disease. Gut 2015; 64: 373-380.

2 Hayat JO, Yazaki E, Moore AT, et al. Objective detection of esophagopharyngeal reflux in patients with hoarseness and endoscopic signs of laryngeal inflammation. J Clin Gastroenterol 2014; 48: 318-327.

3 Ocak E, Kubat G, Yorulmaz I. Immunoserologic pepsin detection in the saliva as a non-invasive rapid diagnostic test for laryngopharyngeal reflux. Balkan Med J 2015; 32: 46-50.

4 de Bortoli N, Savarino E, Furnari M, et al. Use of a non-invasive pepsin diagnostic test to detect GERD: correlation with MII-ph evaluation in a series of suspected NERD patients. A pilot study. Gastroenterology 2013; 144: S118.

5 Savarino E, Carbone R, Marabotto E, et al. Gastro-oesophageal reflux and gastric aspiration in idiopathic pulmonary fibrosis patients. Eur Respir J 2013; 42: 1322-1331.

Morice AH. Chronic cough hypersensitivity syndrome. Cough 2013; 9: 14

Morice AH, Faruqi S, Wright CE, et al. Cough hypersensitivity syndrome: a distinct entity. Lung 2011; 189: 73-79. Everett CF, Morice AH. Gastroesophageal reflux and chronic cough. Minerva Gastroenterol Dietol 2004; 50: 205-213.

9 Vardar R, Sweis R, Anggiansah A, et al. Upper esophageal sphincter and esophageal motility in patients with chronic cough and reflux: assessment by high-resolution manometry. Dis Esophagus 2013; 26: 219-225.

10 Bohman JK, Kor DJ, Kashyap R, et al. Airway pepsin levels in otherwise healthy surgical patients receiving general anesthesia with endotracheal intubation. Chest 2013; 143: 1407-1413.

11 Elabiad MT, Zhang J. Detection of pepsinogen in the neonatal lung and stomach by immunohistochemistry. J Pediatr Gastroenterol Nutr 2011; 53: 401-403.

12 Strugala V, Dettmar PW, Bardhan KD, et al. Optimisation of the Peptest diagnostic test for detection of GORD using pepsin as a marker: an ideal primary care tool. Gut 2015; 64: Suppl. 1, A492-A493.

13 Faruqi S, Molyneux ID, Fathi H, et al. Chronic cough and esomeprazole: a double-blind placebo-controlled parallel study. Respirology 2011; 16: 1150-1156.

14 Morice AH, Kastelik JA. Cough. 1: Chronic cough in adults. Thorax 2003; 58: 901-907.

Eur Respir J 2016; 47: 339-341 | DOI: 10.1183/13993003.00827-2015 | Copyright @eES 2016 